\title{
Platforms for Bioorthogonal Oligonucleotide-templated Reactions: Translating Concepts into Devices
}

\author{
Suraj Pavagada and Sylvain Ladame*
}

\begin{abstract}
The exponential improvements made in DNA sequencing technologies, together with the rapidly declining associated costs, has increasingly led to the expansion of the field of personalised genomic medicine. Changes in the sequence or copy number of specific deoxyribonucleic acid (DNA) or ribonucleic acid (RNA) molecules represent key signatures for the diagnosis, prognosis, classification and monitoring of a broad range of pathologies, most notably cancer. Technologies that can detect these changes require analytical tools that can detect DNA or RNA with high sensitivity and high specificity. Sensing based on bioorthogonal oligonucleotide-templated reactions (OTRs) has been recognised as an elegant strategy that satisfies these criteria and was successfully used for the quantitative detection of nucleic acids both in vitro and in vivo. Herein, we will focus on recent efforts to implement bioorthogonal OTRs into clinically useful biosensors using probes immobilised on or embedded in customised materials and platforms.
\end{abstract}

Keywords: Oligonucleotide-templated Reaction · Sensing · Hydrogel · Diagnostic · Paper-microfluidic

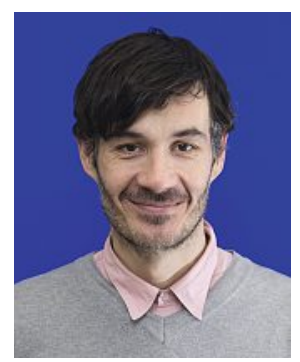

Dr. Sylvain Ladame (FRSC) received his $\mathrm{PhD}$ in Chemistry of Biomolecules from the University of Toulouse (France) in 2001 before moving to Cambridge (UK) to work for five years as a post-doctoral researcher in the group of Sir Prof. Shankar Balasubramanian. In 2006, he started his independent research career as a junior group leader within the Institute of Science and Supramolecular Engineering (ISIS, Strasbourg, France) before being appointed lecturer at Imperial College London in 2010 where he is currently employed as a senior lecturer in biosensor development within the Department of Bioengineering. Sylvain has worked in the field of nucleic acids for over fifteen years and now specialises in the engineering and validation of novel non-invasive and low-cost diagnostic tests based on the detection of circulating, cell-free nucleic acids (DNA and RNA) in liquid biopsies. Applications range from early diagnosis and improved prognosis of prostate cancer to early prediction of pre-term birth. Sylvain has published over 50 papers and has two patents to his name.

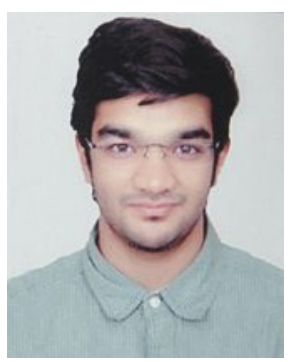

Suraj Pavagada received his Master's in Research (MRes) degree in Medical Device Design and Entrepreneurship from Imperial College London in 2017. He was awarded a scholarship from the Inlaks Shivdadsani Foundation to pursue his master's research focusing on the development of low-cost sensors for circulating microRNAs. Suraj is currently employed as a Research Assistant in the Department of Bioengineering at Imperial College London. Before joining Imperial, Suraj completed his Bachelor of Engineering (BE) degree in Biotechnology at PES Institute of Technology (Bangalore, India) in 2016. Suraj's prior experiences lie in the field of molecular oncology with a primary focus on implementing liquid biopsies for various cancers and prenatal disorders.

\section{Introduction to Bioorthogonal Oligonucleotide-templated Reactions (OTRs)}

As of March 2018, there were almost 75,000 actively marketed genetic testing products in the United States alone. The number of new gene testing products entering the global market is accelerating at an unprecedented rate, owing to the drastic improvements made in sequencing technologies, together with the rapidly declin- ing associated costs. ${ }^{[1]}$ Moving forward, affordable full genome sequencing may help identify biomarkers for diagnosis of multifarious diseases. However, it is unlikely to replace snapshots provided through simple technologies that can be used either in research laboratories or in clinics, to screen, diagnose and monitor individual patients at the point of care.

Nucleic acids have risen to the forefront of molecular diagnostics as effective biomarkers for a plethora of diseases. The vast array of data from sequencing studies of patient-derived tissues has led to the discovery of various nucleic acid species that can accurately represent the current state of the disease. ${ }^{[2]}$ In addition, circulating cell-free nucleic acids (including microRNAs and viral DNA/RNAs) have gained immense popularity for applications in minimally-invasive diagnostics. ${ }^{[3,4]}$

The availability of such validated biomarkers, especially in biofluids (including blood, urine or saliva) has increasingly led to their use to guide clinical decisions through the development of nucleic acid-based tests (NATs). ${ }^{[5]}$ These NATs have been successfully utilised for early diagnosis, ${ }^{[6]}$ monitoring of disease progression ${ }^{[7]}$ and for testing of drug sensitising mutations. ${ }^{[8]}$ As such, there is a great demand for sensing technologies that can detect nucleic acid sequences in cells, biological fluids, and even directly in the living body, efficiently enough to be implemented in clinics and research laboratories. ${ }^{[9]}$

Sensing strategies based on bioorthogonal oligonucleotide-templated chemistries have recently emerged as highly 
promising for the detection of endogenous nucleic acids (NAs) both in vitro and in vivo. ${ }^{[10]}$ Widespread in nature (hence biocompatible), oligonucleotide-templated reactions (OTRs) use a DNA or RNA strand as a template to catalyse an unfavourable bimolecular chemical reaction by significantly increasing the effective molarity of two monomers otherwise present in solution at too low concentrations to cross-react. ${ }^{[11]}$ The general mechanism relies on sequence-specific Watson-Crick base pairing between the template strand and two engineered oligonucleotide probes (functionalised with carefully designed probe-heads), to facilitate a proximity-induced bioorthogonal chemical reaction and unleash a detectable signal (Fig. 1). ${ }^{[12,13]}$ The bioorthogonality of the chosen oligonucleotide-templated chemistry enables OTRs to be suitable for a wide range of applications, including controlled organic synthesis ${ }^{[14]}$ and programmed drug release. ${ }^{[15]}$ However, this review will focus exclusively on applications of OTRs for in vitro sensing of NA biomarkers.

The flexibility of OTRs, with their ability to be engineered for a variety of readout strategies based on carefully chosen bioorthogonal chemistries make them a very attractive technology for incorporation in NA sensing platforms. The aim of this minireview is to report some of the recent ef- forts to implement these NA-templated bioorthogonal chemistries into devices via incorporation of engineered probes into suitable platforms and matrices. In doing so, we wish to highlight the potential of OTR-based sensing platforms as rational alternatives to conventional platforms for detection of NA biomarkers.

\subsection{General Merits of Bioorthogonal OTR-based NA Sensing Strategies}

The two main issues associated with nucleic acid-based diagnostic tests are selectivity and sensitivity. High selectivity is sought when discrimination between sequences with single base variations is required, and high sensitivity is sought when the target is present in very low concentrations in the chosen medium. ${ }^{[16]}$ It is therefore crucial for the sensor's performances to be tailored to the chosen target. ${ }^{[17]}$

It has been shown that bioorthogonal OTRs can be engineered that rival the most selective enzymes. ${ }^{[18]}$ For optimal specificity at the single nucleotide level, peptide nucleic acid (PNA)-based probes have been commonly used as an alternative to standard oligonucleotides since they are more responsive to point mutations. ${ }^{[19]}$ With their charge-free 2-aminoethyl glycine (AEG) backbone mimicking the negatively charged phosphodiester-sugar present in standard oligonucleotides, PNAs exhibit

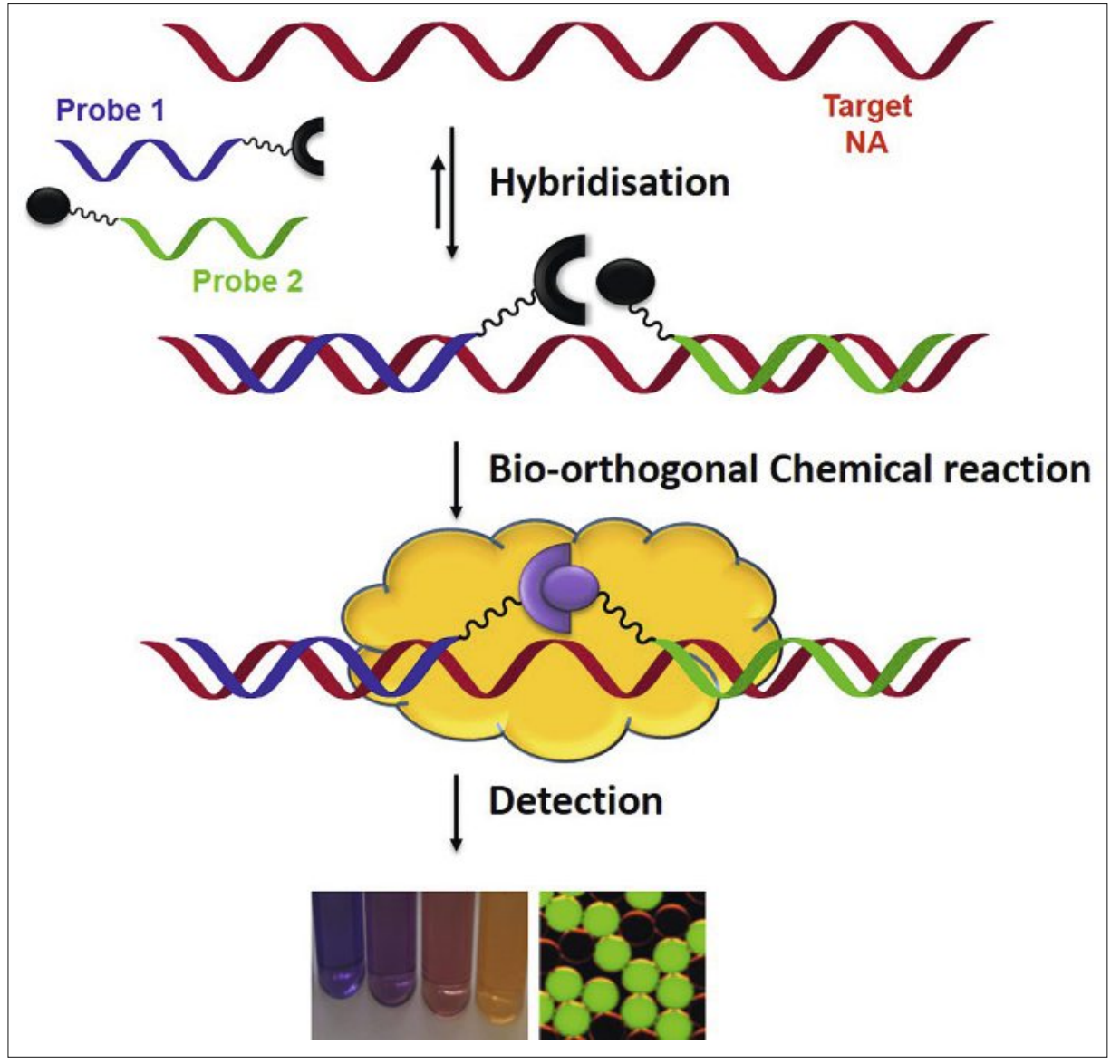

Fig. 1. Schematic representation of a typical bioorthogonal oligonucleotide-templated reaction (OTR) applied to NA sensing.

stronger binding affinity to complementary DNA (or RNA), thus contributing to improved specificity and sensitivity. ${ }^{[16]}$ High sensitivities were also reported for OTRbased sensors using enzyme-free signal amplification strategies. ${ }^{[20]}$ Whilst common ways to detect low copy numbers of NAs require target pre-amplification using DNA or RNA polymerases (as in PCR), OTRspecific signal amplification via catalytic turnover also proved highly successful, where the same NA template can catalyse more than one chemical reaction. ${ }^{[21]}$

Overall, OTR-based technologies are better suited for in vitro sensing applications compared to conventional techniques, owing to their simple workflow, cost-effectiveness and compatibility with multiple readout formats. ${ }^{[10]}$ They have successfully been used for sensing single-stranded, double-stranded and four-stranded (e.g. G-quadruplexes) NA structures. ${ }^{[22-24]}$ OTR-based technologies therefore have the potential to play a key role in the next generation of biomedical diagnostic devices, assuming they can be easily incorporated into suitable (ideally low-cost) platforms.

OTRs can broadly be classified based on the readout strategy employed (defined by the chosen bioorthogonal chemistry), as being either optical or size-based. Optical readout formats mainly include fluorescence-based systems that can be monitored quantitatively using fluorescence microscopes/scanners or flow cytometers, and bioluminescence-based approaches that are detectable with luminescence spectrometers or with the naked eye. ${ }^{[10]}$ OTRs with a colorimetric readout have also been reported on enzyme linked immunosorbent assay (ELISA) and paper-based formats.[25,26] Finally, products of ligation-mediated templated reactions can be detected by size/ molecular weight-based approaches that use gel electrophoresis (including denaturing polyacrylamide gel electrophoresis (PAGE)), high performance liquid chromatography (HPLC) and mass spectrometry systems such as the matrix assisted laser desorption and ionisation-time of flight (MALDI-TOF) technique. ${ }^{[27,28]}$

\subsection{Templated Reactions in Solution: Overcoming Sensitivity Issues}

Most early examples of OTRs were ligation reactions carried out in solution and were solely monitored using platforms such as HPLC, mass-spectrometry and/ or gel electrophoresis to confirm the presence of the desired ligation products. ${ }^{[29,30]}$ However, such size-based detection approaches suffer from several analytical drawbacks, such as the need for multiple steps of isolation and characterisation of the ligated products, and the inability to produce quantitative readouts. ${ }^{[11]}$ 
Bioorthogonal fluorogenic OTRs were then engineered that can be monitored by measuring the fluorescence emitted by the reaction product in situ. ${ }^{[31-33]}$ In such cases, fluorescence intensity is directly proportional to the amount of NA target present in solution, thus enabling quantitative detection of NA biomarkers. However, the main challenge in using fluorescence-based OTRs in solution, is sensitivity, which can be compromised easily by background noise originating from either incomplete quenching of the fluorogenic probe heads before addition of template, or from non-templated reactions between probes occurring despite the absence of the template. ${ }^{[34]}$

To overcome this issue of sensitivity and enable the detection of low copy numbers of endogenous NA biomarkers, strategies that prevent product inhibition have been developed where the NA target can dissociate from the OTR product and be recycled for catalytic turnover to occur. ${ }^{[35]}$ This can be achieved via either thermocycling (alternating heat cycles to favour product formation and product dissociation) and/or the use of additional reagents. ${ }^{[36]}$ Alternatively, reactions that do not yield a ligation product have also been reported with efforts to broaden the bioorthogonality and accelerate OTRs to maximise turnover frequency. [37]

\section{OTR Platforms Used for in vitro Sensing of Nucleic Acids}

While bioorthogonal reactions in solution enable a broad range of chemistries and applications, tethering OTR probes onto solid supports (either during the sensing process or post-reaction to facilitate detection) provides a great opportunity to address some of the limitations of solution-based approaches discussed above. Immobilisation of OTR probes onto low-cost solid supports and localised embedding in hydrogel matrices are two strategies recently reported to increase signal-to-noise ratio by spatially concentrating the readout signal and/or reduce background noise. Such innovations could pave the way to the next generation of low cost NATs based on bioorthogonal OTR sensing (Fig. 2).

\subsection{OTRs on Beads}

Magnetic beads are commonly used for specific or non-specific purification (or enrichment) of NAs from biofluids prior to amplification and detection. ${ }^{[38,39]} \mathrm{A}$ beadbased flow cytometric approach was recently developed for the sensitive detection of plant microRNAs (or miRNAs). This strategy, described by Fan et al., [40] is based on a two-step cascading signal amplifica-

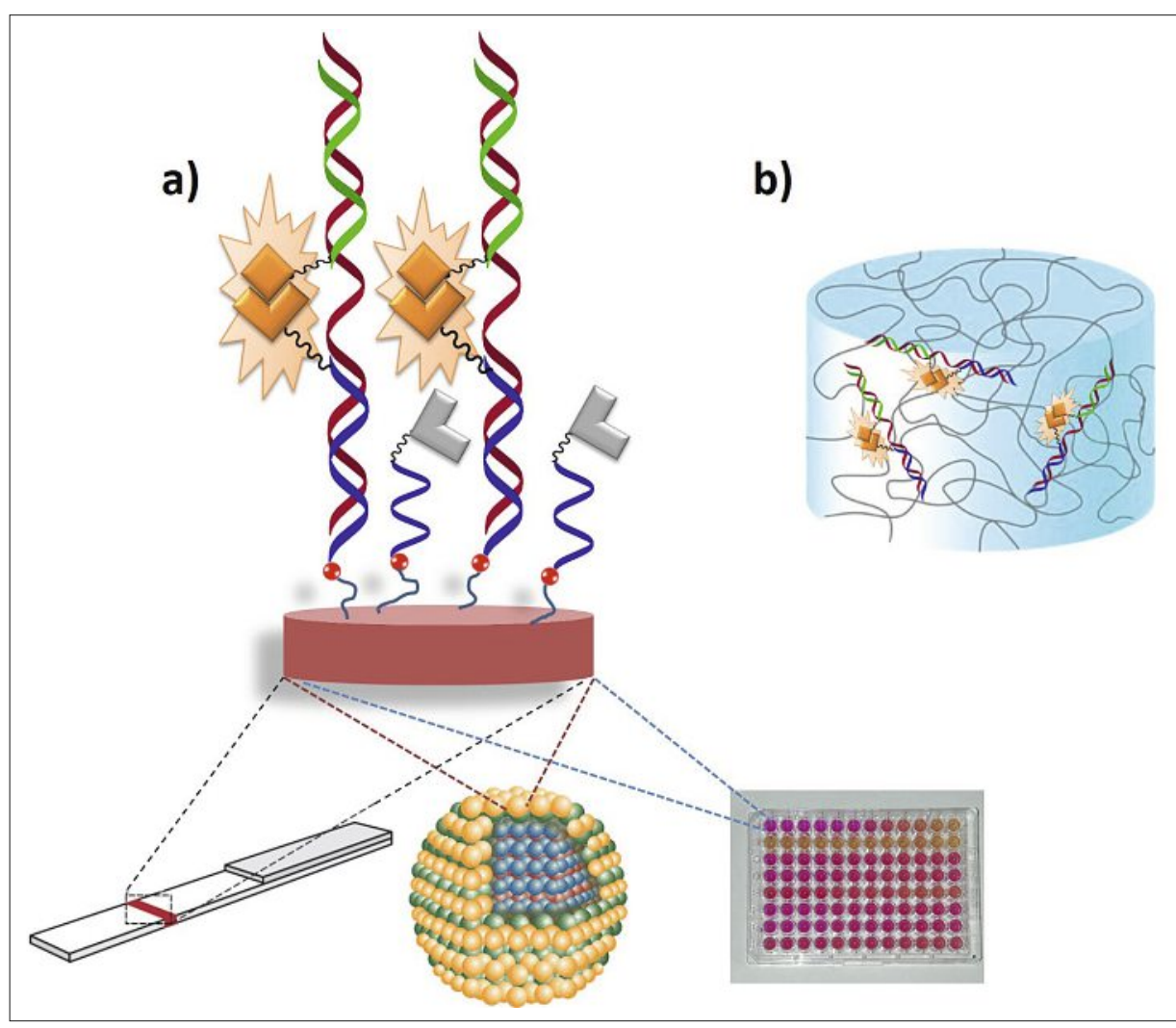

Fig. 2. Schematic representation of recently developed platforms suitable for bioorthogonal OTRs where probes are either a) immobilised on surfaces or b) embedded in biomaterials.

tion that involves target-templated cycling click nucleic acid ligation (CCNAL) and the subsequent terminal deoxynucleotidyl transferase (TdT)-catalysed terminal enzymatic DNA polymerization (TEP) on the surface of magnetic beads (MBs). Recently, the enzyme-free and copper-free chemistry of click nucleic acid ligation (CNAL) reaction has become a powerful tool for the templated ligation of two ssDNA molecules modified with Azadibenzocyclooctyne (Aza-DBCO) and azide $\left(\mathrm{N}_{3}\right)$, respectively. The CCNAL-TEP assay offers several advantages for sensing purposes. First, the undesirable non-templated (hence non-specific) ligation between the modified probes, commonly occurring in traditional solution-based reactions can be completely suppressed, thereby enabling each miRNA template to undergo many rounds of enzyme-free CNAL reaction. This leads to the generation of multiple ligation products and subsequent accumulation of fluorophores on the MBs via thermo-cycling. Also, flow cytometric analysis enables the optical information on each fluorophore-enriched MB to be directly interrogated without the need for any separation or fluorophore elution procedures. This provides a powerful and easy-to-use analytical tool with a reported limit of detection of plant miRNA at $5 \mathrm{fM} .{ }^{[40]}$

Another interesting approach utilising OTRs on beads was described by Velema et $a l .{ }^{[41]}$ The study represents a new strat- egy for attaining higher-order signal amplification, directly in biological samples, without the need for prior isolation or purification of the NA analyte. The coupling of two bioorthogonal OTRs is used to attain quadratic signal formation. Both templated reactions take place non-enzymatically and isothermally, and the initiation of the replication process depends solely on the presence of a specific target sequence. In the proposed system, termed as Fluorogenic Amplified Cascaded Templated Reactions (FACTR), the signalling probes were immobilised on PEG-polystyrene beads that also retained the fluorescence products resulting from the cascading OTRs. Using this approach, as little as 500 attomoles of a specific target could be detected with single nucleotide resolution. ${ }^{[41]}$

\subsection{OTRs on Glass Surfaces}

DNA chip technology uses microscopic arrays of DNA molecules on solid supports (typically glass) for DNA computing, as well as for biomedical analysis such as gene expression analysis, polymorphism or mutation detection, DNA sequencing and biomarker discovery. ${ }^{[42-44]}$ In a landmark study, Ogasawara et al. reported the incorporation of template-directed photoligation reactions on a DNA chip. ${ }^{[45]}$ This study represented the first surface photoligation technology and presented results indicating its ability to achieve single base discrimination, after irradiation at $366 \mathrm{~nm}$ for $60 \mathrm{mins}$ at room temperature. 
In another study described by Yoshimura et al., RNA mismatches were successfully distinguished by using a similar DNA chip assay based on photo ligation reactions, without any by-product formation. The study reported efficient template-directed and bioorthogonal photoligation of oligodeoxynucleotides (ODNs) using 5-carbamoylvinyl-2'-deoxycytidine $\left({ }^{\mathrm{CV}} \mathrm{C}\right)$. Single nucleotide differences in RNA could be successfully distinguished using this photoligation-based DNA chip assay using a fluorescence microarray scanner.[46] Further studies employing similar ${ }^{\mathrm{CV}} \mathrm{U}$-based chemistries were illustrated for improved detection of SNPs in DNA, including a two-colour detection platform that facilitates SNP typing of heterozygous samples. ${ }^{[47,48]}$ None of these OTRbased DNA chips require any enzymes or time-consuming steps, as opposed to most conventional SNP detection systems (such as RT-PCR and traditional SNP arrays). In addition, the bioorthogonal photo-reversibility of the ODNs containing ${ }^{\mathrm{CV}} \mathrm{U}$, allows for recycling of the DNA chip, further reducing the cost of testing. [49] Therefore, these platforms present significant advantages over solution-based OTRs.

While most analytical techniques still utilise a fluorescence-based readout, there have been efforts to employ luminescence-based detection strategies on microarray formats. Karhunen et al. described the first example of a wash-free nucleic acid array using lanthanide luminescence as the detection method. ${ }^{[50]}$ In the proposed system, labelled oligonucleotide capture probes were spotted in streptavidin-coated 96-well plates. In the presence of a complementary target oligonucleotide, the spotted capture probe and a corresponding detection probe hybridised adjacent to the target to form a luminescent europium (III) complex on the glass surface. The resulting luminescence signal could be measured in situ (i.e. no washing steps required) and in time-resolved mode by scanning from the bottom of the wells. In the absence of a complementary target oligonucleotide, the detection probe remained in the liquid phase and was therefore undetectable at the spot. This homogeneous solid-phase array-based method resulted in quantitative detection of synthetic target oligonucleotides with a sensitivity in the $\mathrm{nM}$ range. ${ }^{[50]}$ When compared to traditional organic fluorophores, luminescent lanthanide ions or complexes offer the advantage of a longer emission lifetime, sharper emission peaks and typically larger Stokes' shift.[51] This makes DNA microarray technology utilising templated lanthanide chelates a promising platform for highly selective and robust detection of NA targets.

In addition to fluorescence and luminescence-based readouts, an OTR system for colorimetric detection of RNA targets on Ni-coated well plates was described by Grossmann et al. ${ }^{[25]}$ The study reported the bioorthogonal, RNA-catalysed, transfer of a biotin reporter to a His6-tagged PNA that allowed the preamplification of viral RNA for an ELISA readout. This tandem amplification of the RNA target enabled a detection limit of 500 attomoles of human immunodeficiency virus-( HIV-I) RNA using a simple colorimetric readout. [25] This platform demonstrated sensitive detection of RNA targets, using a common plate reader when most other sensitive detection methods require specialised equipment.

\subsection{OTRs on Functional Nanocomposites}

Fluorescent nanoprobes are widely considered as powerful tools for ultrasensitive biosensing, due to their technical simplicity, high sensitivity to NAs and their ability to provide quick results. ${ }^{[52]}$ There have been numerous studies that employ nucleic acid templates for nanomaterial functionalisation, which have found applications in sensitive biomolecular sensing. ${ }^{[53,54]}$ However, most of these studies rely on structural modifications of the probes/nanoparticles to generate an optical signal.

In 2014, Oliver Seitz et al. reported a proof-of-concept study for OTRs on the surface of nanosized Quantum Dots (QD). In the proposed method, a DNA template brought together two reactive oligonucleotide probes, thereby inducing a proximity-triggered and bioorthogonal transfer reaction. This template-generated transfer eventually led to the covalent attachment of a fluorescence dye on the surface of a quantum dot (QD) for sensitive and quantitative detection. ${ }^{[55]}$ Recently, a study from the same group presented a modified design for implementing OTRs on QDs with improved reaction kinetics and sensitivity. In contrast to the previously reported strategy of proximity-driven FRET, the new system utilises the ability of one RNA molecule to trigger multiple dye transfer processes, thereby resulting in higher sensitivity. ${ }^{[56]}$ The QD based FRET-system also allows for multiplexing by simply varying the size of the nanomaterial.

Finally, since the proposed assay can be read with very simple instrumentation (e.g. a filter-based fluorescence sensor), and is applicable to any kind of polymer-coated nanoparticle (including Cd-free QDs), it has the potential to be implemented in point-of-care testing schemes (POCT), with advanced detection capabilities.

\subsection{OTRs within Hydrogel Matrices}

Numerous studies have previously utilised hydrogel matrices to purify and characterise OTR products. ${ }^{[57-59]}$ However, embedding engineered OTR probes within hydrogel matrices for sensing, is an area that remained unexplored until recently.

A recent study from Ladame et al. reported the first examples of fluorogenic OTRs carried out within physical hydrogels. ${ }^{60]}$ In this novel platform, fluorogenic PNA probes were engineered that can detect NA biomarkers via OTR when embedded within permeable agarose and alginate hydrogels. In addition to being the first example of OTR carried out in physical hydrogel, this study demonstrated that restricted mobility (that is, limited diffusion) of the probes within the hydrogel could drastically prevent non-specific interactions in the absence of NA template, even under unusually large probe concentrations. This resulted in lower background signals and higher signal-to-noise ratio (SNR) when compared to similar reactions carried out in solution. Probes encapsulated by biologically localized embedding (PEBBLE) biosensors were also developed that consisted of spherical alginate beads containing a stoichiometric mixture of PNA probes and that could detect DNA concentrations as low as $100 \mathrm{pM} .{ }^{[60]}$ Permeable hydrogels such as agarose or alginate could therefore represent low-cost, easily modifiable matrices for the next generation of OTRbased optical NA sensors. Whilst the same probes in solution were shown to detect endogenous concentrations of circulating miRNAs in human blood, without the need for any amplification step, ${ }^{[33]}$ further improvement of the LOD by embedding the probes within permeable hydrogels could ensure that even the least abundant miRNAs can be detected.

\subsection{OTRs in Lateral Flow Assays (LFAs)}

In recent years, paper has become a popular material for making bioanalytical devices, due to its characteristics of affordability, sustainability, portability, disposability, simplicity, and ability to handle very small volumes of samples, such as blood, urine, and saliva. ${ }^{61,62]}$

With the introduction of home diagnostic tests for pregnancy, lateral flow assays (LFA) gained wide popularity as a simple low-cost testing platform for molecular diagnostics. ${ }^{[63]} \mathrm{A}$ vast number of serological immunoassays based on lateral flow mechanisms have now been developed and find applications in many areas including food safety, environmental monitoring, and veterinary diagnostics. ${ }^{[64]}$

However, working with LFAs presents several challenges such as poor detection limits and low sensitivities that confine their applications. ${ }^{[65]}$ To overcome these limitations, efforts are being made, that include incorporation of micropillars, PDMS, agarose and sponges on the LFA to effectively reduce the rate of flow through 
the cellulose paper.[66-69] This would increase the time for the molecules in mobile phase to interact with those on the test line, and ultimately improve the signal output. [70]

Another approach to improving the limitations of conventional LFAs would be to implement OTRs on paper, for rapid and low-cost detection of NA targets. Winssinger et al, recently reported the design of a LFA for rapid detection of the products of template-mediated bioorthogonal ligations. ${ }^{[26]}$ Two synthetic PNA probes were functionalised with probe heads that can undergo a peptide bond formation under a selenium-mediated ligation manifold exclusively upon simultaneous hybridisation to a unique NA target. Insertion of a lateral flow test strip into the sample solution containing the ligation products, would then provide a rapid indication of the presence/absence of the desired target sequence. This was achieved by further modification of the PNA probes with biotin and fluorescein tags. The biotin enabled capture of the OTR product on a streptavidin-coated test line whilst fluorescein (FITC) was used for colorimetric detection (visible to the naked eye) via anti-FITC antibody coated gold nanoparticles. This method also demonstrated the ability to detect miRNAs in crude lysates, thus presenting significant advantages over conventional platforms that require extensive sample processing prior to detection.

\section{Conclusion and Future Directions}

The volume of PoC tests has steadily increased over the last 40 years or so and this growth is likely to continue, driven by changes in healthcare delivery which are aimed at delivering affordable care closer to the patient's home. ${ }^{[71]}$ Interestingly, a large number of those tests rely on NA biomarkers. ${ }^{[61,72]}$ Current available NA detection technologies such as real-time polymerase chain reaction (RT-PCR), northern blotting and microarray analysis already offer highly accurate and sensitive detection. However, most of these conventional methods are hindered by complicated and expensive procedures, time consuming target amplification steps and/or limited sensitivity. These limitations severely restrict the practical applications of such methods, especially in the field. ${ }^{[73]}$ Therefore, there is a great need for the development of rapid, widely-applicable and operationally simple nucleic acid detection systems and sensing strategies based on bioorthogonal OTRs have the potential to play a key role in the next generation of PoC tests. ${ }^{[74-76]}$ OTR-based platforms have shown the ability to detect several types of NA targets including single and double stranded DNA, RNA, miRNA and G-Quadruplex, presenting several design-specific advantages over the conventional alternatives. Each platform and each bioorthogonal OTR (summarised in Table 1) come with their own set of unique advantages and challenges that make them better suited for

Table 1. Summary of NA sensing platforms based on bioorthogonal OTR

\begin{tabular}{|c|c|c|c|c|c|c|}
\hline Platform & Solid Support & $\begin{array}{c}\text { Bioorthogonal } \\
\text { Chemistry }\end{array}$ & Target & Sensitivity & $\begin{array}{l}\text { Readout } \\
\text { Strategy }\end{array}$ & Ref. \\
\hline \multirow[t]{2}{*}{ Beads } & $\begin{array}{l}\text { Dynabeads M-270 } \\
\text { Streptavidin } \\
\text { (STV-MBs) }\end{array}$ & $\begin{array}{l}\text { Cyclic Click Nucleic } \\
\text { Acid Ligation }\end{array}$ & miRNA & $5 \mathrm{fM}$ & $\begin{array}{c}\text { Flow } \\
\text { Cytometry }\end{array}$ & [40] \\
\hline & $\begin{array}{l}\text { Oligo Affinity } \\
\text { Support (PS) }\end{array}$ & $\begin{array}{c}\text { Chemical } \\
\text { Autoligation + } \\
\text { Staudinger Azido- } \\
\text { ether Reduction }\end{array}$ & 16S rRNA & $500 \mathrm{aM}$ & $\begin{array}{l}\text { Epifluores- } \\
\text { cence } \\
\text { Microscope }\end{array}$ & [41] \\
\hline \multirow[t]{3}{*}{ Glass Surface } & $\begin{array}{l}\text { Aldehyde modified } \\
\text { Glass Surface }\end{array}$ & $\begin{array}{l}\text { Photoligation using } \\
\text { 5-carbamoylvinyl-2'- } \\
\left.\text { deoxycytidine ( }{ }^{\mathrm{Cv} U}\right)\end{array}$ & RNA & aM range & $\begin{array}{l}\text { Microarray } \\
\text { Scanner }\end{array}$ & [46] \\
\hline & $\begin{array}{l}\text { Aldehyde modified } \\
\text { Glass Surface }\end{array}$ & $\begin{array}{l}\text { Photoligation using } \\
\text { 5-carbamoylvinyl-2'- } \\
\left.\text { deoxycytidine ( }{ }^{\mathrm{CV}} \mathrm{U}\right)\end{array}$ & DNA & aM range & $\begin{array}{l}\text { Microarray } \\
\text { Scanner }\end{array}$ & [47] \\
\hline & Ni Coated Well Plate & $\begin{array}{l}\text { RNA-catalyzed } \\
\text { transfer of a biotin } \\
\text { reporter }\end{array}$ & RNA & $500 \mathrm{aM}$ & $\begin{array}{c}\text { ELISA } \\
\text { (Colorimetric) }\end{array}$ & {$[25]$} \\
\hline \multirow[t]{2}{*}{$\begin{array}{c}\text { Functional } \\
\text { Nanocomposites }\end{array}$} & $\begin{array}{l}\text { Quantum dot (QD } \\
\text { 605) with CdSe-ZnS } \\
\text { core-shell nanocrystal }\end{array}$ & $\begin{array}{c}\text { Templated Single } \\
\text { Dye Transfer }\end{array}$ & DNA & $\begin{array}{l}35 \mathrm{nM} \text { at } 5 \mathrm{nM} \\
\mathrm{QD} \text { concentra- } \\
\text { tion }\end{array}$ & FRET & {$[55]$} \\
\hline & $\begin{array}{l}\text { Quantum dot (QD } \\
\text { 605) VIVID carboxyl }\end{array}$ & $\begin{array}{c}\text { Templated Multiple } \\
\text { Dye Transfer }\end{array}$ & RNA & $\begin{array}{l}10 \mathrm{pM} \text { to } \\
100 \mathrm{nM}\end{array}$ & $\begin{array}{l}\text { FRET/ time } \\
\text { resolved } \\
\text { luminescence }\end{array}$ & {$[55]$} \\
\hline Hydrogel Matrices & $\begin{array}{l}\text { Alginate Beads } \\
\text { (PEBBLE Sensor) }\end{array}$ & $\begin{array}{c}\text { Fluorescence } \\
\text { unquenching from } \\
\text { Michael-addition }\end{array}$ & DNA & $100 \mathrm{pM}$ & $\begin{array}{l}\text { Fluorescence } \\
\text { Scanner }\end{array}$ & [60] \\
\hline Lateral Flow Assay & $\begin{array}{l}\text { Standard cellulose } \\
\text { paper used in LFAs }\end{array}$ & $\begin{array}{c}\text { Selenocystine- } \\
\text { selenoester peptide } \\
\text { ligation }\end{array}$ & DNA & $0.1 \mathrm{nM}$ & $\begin{array}{l}\text { Colorimetric } \\
\text { Readout }\end{array}$ & [26] \\
\hline
\end{tabular}


specific applications. Further research and creative utilisation of bioorthogonal OTRs to develop novel platforms or improve currently established platforms represent an exciting path to the development of the next generation of biomedical diagnostic devices.

Received: July 31, 2018

[1] K. A. Phillips, P. A. Deverka, G. W. Hooker, M. P. Douglas, Health Aff. 2017, 37, 710.

[2] R. Weiner, M. K. Russell in 'Translating Molecular Biomarkers into Clinical Assays: Techniques and Applications', Springer, 2016.

[3] S. P. Suraj, C. Dhar, S. Srivastava, Biomed. Rep. 2017, 6,8 .

[4] O. Pös, O. Biró, T. Szemes, B. Nagy, Eur. J. Human Genet. 2018, 26, 937.

[5] R. Hans, N. Marwaha, Asian J. Transfus. Sci. 2014, $8,2$.

[6] J. I. A. Rashid, N. A. Yusof, Biosci. Biotech. Res. Asia 2018, 15, 245.

[7] F. Cobo, Open Virol. J. 2012, 6, 104.

[8] K. Goto, M. Satouchi, G. Ishii, K. Nishio, K. Hagiwara, T. Mitsudomi, J. W. E. Donald, R. McCormack, T. Todo, Ann. Oncol. 2012, 23 , 2914.

[9] A. P. Silverman, E. T. Kool, Chem. Rev. 2006, 106, 3775 .

[10] K. Gorska, N. Winssinger, Angew. Chem. Int. Ed. 2013, 52, 6820.

[11] C. Percivalle, J.-F. Bartolo, S. Ladame, Org. Biomol. Chem. 2013, 11, 16.

[12] A. Shibata, H. Abe, Y. Ito, Molecules 2012, 17, 2446.

[13] N. Winssinger, CHIMIA 2013, 67, 340.

[14] X. Li, D. R. Liu, Angew. Chem. Int. Ed. 2004, $43,4848$.

[15] M. Di Pisa, O. Seitz, ChemMedChem. 2017, 12, 872.

[16] T. Grossmann, O. Seitz, Chem. Eur. J. 2009, 15, 6723.

[17] R. J. Benjamin, Semin. Hematol. 2001, 38, 11.

[18] T. N. Grossmann, A. Strohbach, O. Seitz, ChemBioChem. 2008, 9, 2185.

[19] Y. Choi, G. Metcalf, M. Haj Sleiman, D. VairTurnbull, S. Ladame, Bioorg. Med. Chem. 2014, $22,4395$.

[20] X.-H. Chen, A. Roloff, O. Seitz, Angew. Chem. Int. Ed. 2012, 51, 4479.

[21] D. Chang, K. T. Kim, E. Lindberg, N. Winssinger, Bioconj. Chem. 2018, 29, 158.

[22] G. Koripelly, K. Meguellati, S. Ladame, Bioconjug. Chem. 2010, 21, 2103.

[23] H. Li, R. Franzini, C. Bruner, E. Kool, ChemBioChem. 2010, 11, 2132.
[24] K. Meguellati, G. Koripelly, S. Ladame, Angew. Chem. Int. Ed. 2010, 49, 2738.

[25] T. Grossmann, L. Röglin, O. Seitz, Angew. Chem. Int. Ed. 2008, 47, 7119.

[26] J. Sayers, J. R. Payne, N. Winssinger, Chem. Sci. 2018, 9, 896.

[27] S. Ficht, A. Mattes, O. Seitz, J. Am. Chem. Soc. 2004, 126, 9970.

[28] Y. Xu, N. B. Karalkar, E. T. Kool, Nat. Biotechnol. 2001, 19, 148.

[29] H. Maruyama, R. Oikawa, M. Hayakawa, S. Takamori, Y. Kimura, N. Abe, G. Tsuji, A. Matsuda, S. Shuto, Y. Ito, H. Abe, Nucleic Acids Res. 2017, 45, 7042.

[30] R. K. Bruick, P. E. Dawson, S. B. Kent, N Usman, G. F. Joyce, Chem. Biol. 1996, 3, 49.

[31] J. Cai, X. Li, X. Yue, J. S. Taylor, J. Am. Chem. Soc. 2004, 126, 16324.

[32] J. Cai, X. Li, J. S. Taylor, Org. Lett. 2005, 7, 751.

[33] G. A. D. Metcalf, A. Shibakawa, H. Patel, A Sita-Lumsden, A. Zivi, N. Rama, C. L. Bevan, S. Ladame, Anal. Chem. 2016, 88, 8091.

[34] J. Berger, M. Oberhuber, Chem. Bioderv. 2010, 7, 2581.

[35] A. Roloff, O. Seitz, ChemBioChem. 2013, 14, 2322.

[36] H. Abe, E. T. Kool, J. Am. Chem. Soc. 2004, 126, 13980.

[37] A. Shibata, T. Uzawa, Y. Nakashima, M. Ito, Y. Nakano, S. Shuto, J. Am. Chem. Soc. 2013, 135, 14172.

[38] S. Berensmeier, Appl. Microbiol. Biotechnol. 2006, 73, 495

[39] J. Oster, J. Parker, L. Brassard, J. Magnetism and Magnetic Mater. 2001, 225, 145.

[40] W. Fan, Y. Qi, L. Qiu, P. He, C. Liu, Z. Li, Anal. Chem. 2018, 90, 5390

[41] W. A. Velema, E. T. Kool, J. Am. Chem. Soc. 2017, 139, 5405.

[42] R. Bumgarner, Curr. Protoc. Mol. Biol. 2013, 22.

[43] J. G. Hacia, L. C. Brody, F. S. Collins, Mol. Psychiatry 1998, 3, 483.

[44] Yoo, S. Min, J. H. Choi, S. Y. Lee, N. C. Yoo, J. Microbiol. Biotechnol. 2009, 19, 635.

[45] S. Ogasawara, K. Fujimoto, Nucleic Acids Symp. Ser. 2005, 49, 145.

[46] Y. Yoshimura, Y. Noguchi, H. Sato, K. Fujimoto, ChemBioChem. 2006, 7, 598.

[47] Y. Yoshimura, D. Okamura, M. Ogino, K. Fujimoto, Org. Lett. 2006, 8, 5049.

[48] A. Takehiro, O. Genki, Y. Yoshinaga, F. Kenzo, Chem. Lett. 2008, 37, 134.

[49] Y. Yoshimura, T. Ohtake, H. Okada, T. Ami, T. Tsukaguchi, K. Fujimoto, Sci. Technol. Adv Mat. 2009, 10, 034603.

[50] U. Karhunen, M. Soikkeli, S. Lahdenperä, T. Soukka, Anal. Chim. Acta 2013, 772, 87.

[51] A. K. Hagan, T. Zuchner, Anal. Bioanal. Chem. 2011, 400, 2847.
[52] X. Su, X. Xiao, Z. Chen, M. Zhao, Appl. Spectrosc. 2012, 66, 1249.

[53] L. Zhou, J. Ren, X. Qu, Mater. Today 2017, 20, 179.

[54] H. Li, T. H. LaBean, K. W. Leong, Interface Focus 2011, 1, 702 .

[55] J. Michaelis, G. J. v. d. H. v. Noort, O. Seitz, Bioconjug. Chem. 2014, 25, 18.

[56] O. Zavoiura, U. Resch-Genger, O. Seitz, Bioconjug. Chem. 2018, 29, 1690.

[57] Y. Xu, N. B. Karalkar, E. T. Kool, Nat. Biotechnol. 2001, 19, 148.

[58] K. Fujimoto, S. Matsuda, N. Takahashi, I. Saito, J. Am. Chem. Soc. 2000, 122, 5646.

[59] M. Nilsson, G. Barbany, D.-O. Antson, K. Gertow, U. Landegren, Nat. Biotechnol. 2000, 18,791 .

[60] D. Al Sulaiman, J. Y. H. Chang, S. Ladame, Angew. Chem. Int. Ed. 2017, 56, 5247.

[61] N. Kaur, B. J. Toley, Analyst 2018, 143, 2213.

[62] A. W. Martinez, S. T. Phillips, G. M. Whitesides, Anal. Chem. 2010, 82, 3.

[63] M. Sher, R. Zhuang, U. Demirci, W. Asghar, Expert Rev. Mol. Diagn. 2017, 17, 351.

[64] G. A. Posthuma-Trumpie, J. Korf, A. van Amerongen, Anal. Bioanal. Chem. 2009, 393, 569.

[65] M. Sajid, A.-N. Kawde, M. Daud, J. Saudi Chem. Soc. 2015, 19, 689.

[66] M. M. Dudek, R. P. Gandhiraman, C. Volcke, S. Daniels, A. J. Killard, Plasma Processes Polym. 2009, 6, 620

[67] J. R. Choi, Z. Liu, J. Hu, R. tang, Y. Gong, S. Feng, H. Ren, T. Wen, H. Yang, Z. Qu, B. Pingguan-Murphy, F. Xu, Anal. Chem. 2016. $88,6254$.

[68] J. R. Choi, K. W. Yong, R. Tang, Y. Gong, T. Wen, H. Yang, A. Li, Y. C. Chia, B. PingguanMurphy, F. Xu, Adv. Healthcare Mater. 2017, 6, 1600920.

[69] R. Tang, H. Yang, Y. Gong, Z. Liu, X. J. Li, T. Wen, Z. Qu, S. Zhang, Q. Mei, F. Xu, Sci. Rep. 2017, 7, 1360 .

[70] B. O'Farrell in 'The Immunoassay Handbook', 4th ed., Elsevier, 2013, p. 89-107.

[71] A. St John, C. P. Price, Clin. Biochem. Rev. 2014, 35, 155.

[72] L. Zhang, B. Ding, Q. Chen, Q. Feng, L. Lin, J. Sun, TrAC Trends in Analytical Chemistry 2017, 94, 106.

[73] M. G. Mauk, J. Song, C. Liu, H. H. Bau, Biosensors 2018, 8, E17.

[74] J. R. Choi, K. W. Yong, R. Tang, Y. Gong, T. Wen, F. Li, B. Pingguan-Murphy, D. Bai, F. Xu, TrAC Trends in Analytical Chemistry 2017, 93, 37.

[75] M. A. Dineva, Lourdes, Mahilum-Tapaya, H. Lee, Analyst 2007, 132, 1193.

[76] J. Gallarda and E. Dragon, Mol. Diagn. 2000, 5, 11 